\title{
Pintura Contemporânea : sua carne, sua alegoria ${ }^{1}$
}

Rosangela Miranda Cherem ${ }^{2}$

Deborah Alice Bruel Gemin ${ }^{3}$

REsumo: Nas discussões de arte contemporânea, o reaparecimento do conceito de alegoria e a persistência da pintura podem ser entendidos como retorno de questões recalcadas. Questões que perscrutam a constituição do corpo pictórico e a sua fala para além da mera visibilidade. Problemática presente nos trabalhos de Adriana Varejão, Nuno Ramos e Caetano de Almeida, cujos trabalhos revelam vestígios da busca do artista desvelada sob a superfície pictórica, e revelam a constituição da visualidade artística como a alegoria do corpo que discute a carne da pintura

P ALAVRAS-ChaVE: pintura alegoria, corpo, arte contemporânea.

Abordar a presença da alegoria na arte contemporânea pode parecer uma questão mal colocada, especialmente se estiver vinculada aos procedimentos pictóricos, já que aparentemente parecem dois assuntos esgotados e ultrapassados. Por sua vez, tal questão constitui-se num modo de abordar a imagem artística não como aquilo que é olhado, mas considerando-a também pelo que se rebate e faz pensar. Remetendo para além de sua visibilidade evidente, tal operação possibilita dizer outra coisa, ou seja ultrapassar o que a obra apresenta em sua materialidade e mera condição formal. A retomada da alegoria nos estudos contemporâneos assim como a persistência da pintura parecem fortalecer a tese do retorno do recalcado, revestido de novas formas para restaurar irresolutas questões.

Bem verdade que grande parte da produção teórica contemporânea acerca da alegoria baseia-se nos estudos de Walter Benjamin, priorizando os procedimentos como indicadores conceituais dos trabalhos de arte, sobretudo aqueles ditos contemporâneos ou pós-modernos como apropriação, montagem e duplicação; bem como problematizam respectivamente a autoria, a anacronia e a originalidade. Contudo tal abordagem parece insuficiente para dar conta de outra questão também importante, ou seja, o próprio corpo do trabalho, aquele que se constitui como obra e se torna um outro, que recebe o olhar do observador e lhe devolve em forma duma existência.

\footnotetext{
${ }^{1}$ Artigo resultante do projeto vinculado ao Grupo de Estudos de Percepções e Sensibilidades do CEART.

${ }^{2}$ Professora do Departamento de Artes Plásticas do Centro de Artes e da linha Teoria e História das Artes Visuais do PPGAV, UDESC.

${ }^{3}$ Mestre pelo PPGAV UDESC, na linha de teoria e História da Arte e participante do grupo de Estudos de Percepções e Sensibilidades do CEART.
} 
Depois de Benjamin, o problema da pintura parece apontar ainda para a questão paradoxal de Merleau Ponty do visível versus tangível e da constituição de um corpo que se vê mas não se toca, que se olha, mas não se traduz. Conforme este filósofo, a carne da obra consiste no "...enovelamento do visível sobre o corpo vidente, Para este filósofo, a carne é uma noção última (...), pensável per si, se há uma relação do visível consigo mesmo que me atravessa e me transforma em vidente, este círculo que não faço mas que me faz, este enrolamento do visível no visível pode atravessar e animar tanto os outros corpos como o meu." "4 A carne da arte consiste na interioridade de seu corpo, pleno de visibilidade, ocultada pela sua superfície/pele, que é apenas o seu limite, carne que se constitui do pensamento, do procedimento e do acúmulo provocado pelo artista e se apresenta como a visualidade de pintura.

Para Didi-Huberman a carne da pintura é a condição para que aconteça o desvio do olho, permindo atravessar da superfície à profundidade, sendo que nesse trajeto de ida e volta acontece uma espécie de atravessamento da tela, desvelando-a e permitindo ao olho expandir-se, pois um quadro é no solamente um tópico, sino una dinâmica y una energética de lo vivo (lo diáfano pensado como una biologia de lo visible). ${ }^{5}$ Tal entendimento parece deliberadamente declarado em trabalhos de alguns artistas brasileiros, diversos entre si e por isso mesmo bastante apropriados para que se possa reconhecer a relação entre o corpo pictórico e a alegoria. Tratando da constituição do corpo como obra e não necessariamente como representação pictórica, permitem refletir sobre esse processo que provoca um pensamento para além de sua superfície e aparência, comparecendo para dizer uma outra coisa, a qual constitui como alegoria da visualidade.

Conforme argumenta Merleau Ponty é preciso sentir ou ver para poder pensar, sendo que todo o pensamento conhecido advém de uma carne, pois ele é relação consigo e com o mundo tanto quanto relação com outrem. Se o ato de ver desperta o desejo do toque, o tocar incita o olhar. A relação imbricada do visível e do tangível dos corpos permite que esta noção de carne englobe a experiência do visível e da produção de sentido que se engendra no corpo da obra. $\mathrm{O}$ ver transubstancia-se ou traveste-se como sentido tátil, porém essa reversibilidade sempre iminente nunca é realizada de fato. ${ }^{6}$

\footnotetext{
${ }^{4}$ PONTY, 2007, p. 136-141.

${ }^{5}$ DIDI-HUBERMAN, 2007, p. 41.

${ }^{6}$ PONTY, op. cit., p. 143.
} 
Vejamos o caso de Adriana Varejão, artista que usa a estética barroca e a azulejaria portuguesa recorrendo à história da arte brasileira e à história da arte ocidental, bagagem através da qual compõe seu discurso como um trabalho de metáforas da memória ${ }^{7}$. Neste sentido, a artista carioca rasga a pele e, revelando o seu corpo, faz uma dissecação da história da matéria viva. Sua pintura permite ser esgarçada para que se enxergue a profundidade, a entranha escondida que sobe à superfície. A espessura sugere que se pode escavar, 'cavocar' as paredes, arrancar os azulejos para descobrir suas entranhas, para ver pulsar o seu corpo e desvendar seus segredos.

Sua obra é tecida nas entranhas e sua poética se constitui na memória desse corpo, problematizando pela matéria plástica a matéria orgânica pertencente ao humano e a matéria inorgânica que pertence à memória na reconstituição de uma identidade histórica e visual. Utilizando-se de fragmentos com eles discute o corpo da arte como matéria que se transforma pela sua operação. Recorre a materiais que simulam outro corpo, parecem carne, mas são espuma, parecem sangue, mas são tinta, parecem azulejo, mas são massa. Procedimento pelo qual recoloca a questão da matéria como aquilo que está alhures, remetendo ao passado e recompondo numa outra estrutura muito mais visceral.

O corpo das suas obras aludem ao mundo da história e suas construções, sinalizando para a constituição ficcional que só o corpo da arte pode criar. Numa operação de montagem de vários processos - desenho, fotografia e escultura - funda a estrutura da obra, que no espaço expositivo parece um fragmento de outro tempo, retirado e resignificado. Daí resulta algo que não é pintura sob uma ótica convencional, embora a isso remeta e sendo suas características mais escultóricas, seu procedimento é muito próximo ao discurso que Didi-Huberman faz da pintura como carne e pele como constitutiva de uma superfície pictórica. Porém, é possível pensar seu corpo a partir do olhar projetado que se frustra sempre por destruir a entidade da superfície, onde a obra funciona como a aporia da projeção. $^{8}$

\footnotetext{
${ }^{7}$ VAREJÃO, Entrevista realizada para a coleção de vídeos Arte na Escola, 2004.

${ }^{8}$ DIDI-HUBERMAN, op.cit., p. 47.
} 


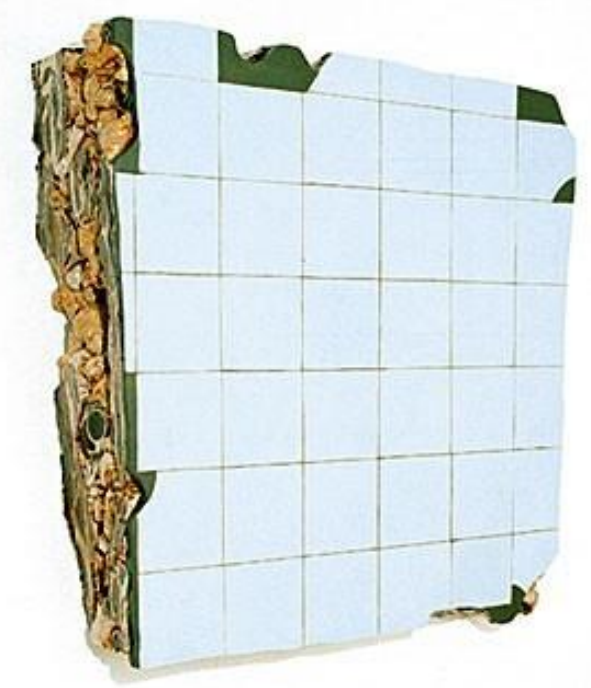

Adriana Varejão, Ruína de Charque Chacahua, 2000.

Outro caso bastante apropriado é o de Nuno Ramos, o qual mesmo que trabalhando com a matéria sob outra ótica, demonstra interesse nas relações entre os diferentes corpos, utilizando-se de parafina e sal, mármore e vaselina, breu e carvão, pedra e espelho para abordar possíveis relações com a natureza do fosco e do brilhante, da dureza e da maleabilidade, do previsível e do incontrolável. Ele apresenta como pintura um corpo, um organismo vivo e orgânico, onde qualquer possibilidade de representação está abolida, confirmando que a experimentação, na qual a ausência de regras é menos um desafio às normas e mais uma maneira de constituir a questão da criação artística que permita a significação, pois a liberdade do artista não passa por um conhecimento artístico e sim por uma vontade espontânea de significar, através da arte, sua perplexidade em relação ao estar no mundo. ${ }^{9}$

Assim, suas telas têm vida própria e se tornam um corpo vivente, completamente alheio à exterioridade do mundo, pois são fragmentos, objetos e pigmentos que se assemelham a organismos autônomos. São seres, mas não se parecem com o humano, se desenvolvem segundo uma lógica própria, que não se pode controlar, sendo que, de maneira diferente de Adriana Varejão, este pretende fazer nenhuma referência à história da

${ }^{9}$ Texto de Alberto Tassinari in:Fichas do Acervo: Roteiro de Visita. Disponível em: http://www.macvirtual.usp.br/mac/templates/projetos/roteiro/PDF/39.pdf. Acesso em 10 mai. 2007. 
pintura, não faz citação e não se inscreve na ordem da representação, pois as relações que estabelece em seus procedimentos e em sua estrutura formal se organizam dentro do próprio corpo do trabalho. Suas grandes pinturas também podem ser vistas como alegorias da pobreza, porque remetem ao resto, aos despojos de carnaval, ao lixo.

Não obstante esta alegoria do significado não seja a discussão pretendida, entendese que sua presença é indiscutível e está relacionada ao contexto político e social do artista. Porém, esta leitura alegórica se refere a um atravessamento que opera pela iconologia dos materiais utilizados e seu significado no mundo, enquanto assinala-se aqui a presença alegórica pela constituição desse corpo pictórico e sua significação para além de sua superfície. As camadas que Nuno Ramos sobrepõe fazem com que a pintura avance em direção ao observador, um corpo que invade o seu espaço. Pode-se dizer que ele rompe a pele-superfície da pintura empurrando seu corpo para fora e assim constituindo seu poder como um ruído. As primeiras camadas de tinta e de matéria que ele põe em sua pintura, muitas vezes nem aparecem ao final do trabalho, ficam escondidas sob outras tantas camadas de dejetos e pigmentos. $\mathrm{O}$ corpo da pintura torna-se um acúmulo de carne que faz da sua superfície-pele uma massa desmórfica, colocando a obra como a capacidade desse corpo se fazer pulsar.

Para Hubert Damish isto se situa como um paradigma da trança, es decir, como uma superfície a cuadros, pero cuya apariencia discontinua sería el resultado del entrecuzamiento, en el espesor del plano de franjas continuas, una franja arriba, una franja abajo $^{10}$. Do mesmo modo tal operação se aproxima à orientação de Cennino Cennini, quando sugere que camadas tenham que ser sobrepostas para revelar a real cor da superfície da pele, e mesmo que a cor da primeira camada não apareça interfere no resultado daquilo que chamamos de superfície, que na verdade é composta por essa trama corpórea. ${ }^{11}$ É aí que também se estabelece a relação com a pele, cuja cor e aparência, só se dá através da diáfana transparência ou névoa e que permite sentir o pulsar do sangue.

\footnotetext{
${ }^{10}$ DAMISCH apud DIDI-HUBERMAN, op.cit., p. 49.

${ }^{11}$ No escrito Il libro dell'arte C.Cennini descreve como devem ser as camadas de tinta acrescidas para que a pele tenha uma cor realista. Deve-se iniciar com um punhado de terra verde (pigmento) acrescido de branco, Sobre essa camada de verde serão acrescidos os rosados, até que a cor da pele esteja correta.Inclusive indica que para a pele dos jovens devem ser usadas as gemas de ovos postos na cidade, por serem mas pálidos que os ovos postos no campo, estes são indicados para produzir a tinta para a pele dos velhos e dos homens morenos. Para Didi-Huberman estas indicações de Cennini concebem O Encarnado. DIDI-HUBERMAN, 2007.
} 


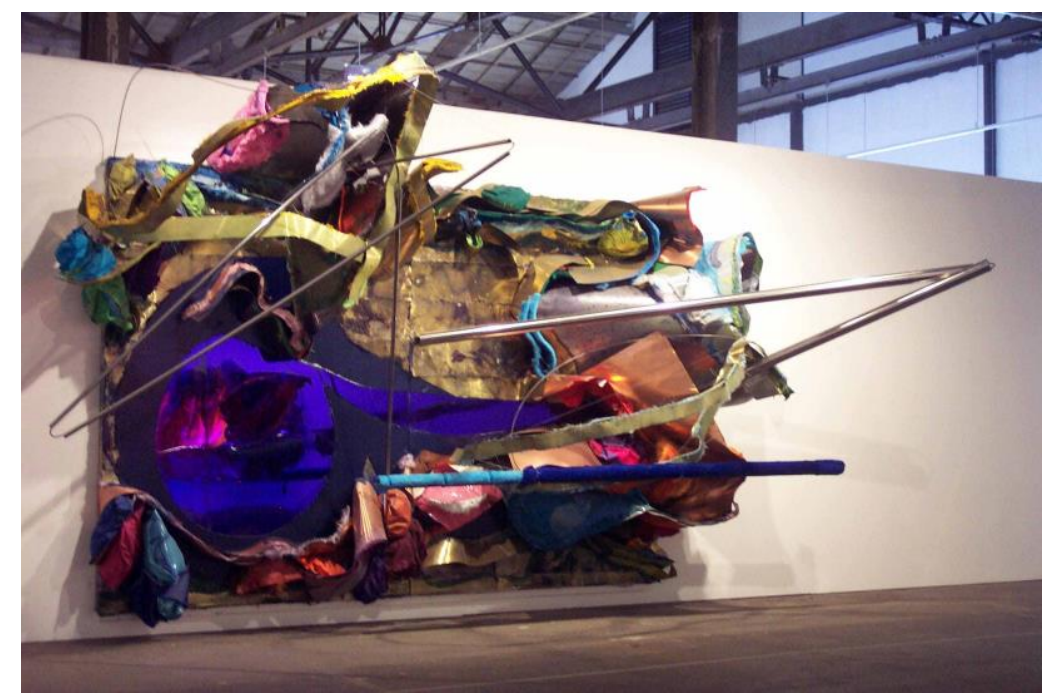

Nuno Ramos, sem título, 2005. 5ª Bienal do Mercosul.

Um terceiro nome que merece ser apresentado para pensar os recursos alegóricos na atualidade e que remete ao enigma da pintura como um corpo é Caetano de Almeida, cuja problematização diz mais respeito à visualidade deste corpo pictórico e suas relações com a história da pintura e constituição do olhar, do que propriamente a construção deste corpo como o faz Nuno Ramos. Nos trabalhos da exposição Borda, Caetano de Almeida faz simulações de tecidos, compondo uma trama muito verdadeira, apesar de ser feita de tinta no lugar dos fios. Trata-se de uma fatura que ironiza a produção, o aparato tecnológico e provoca o olhar, mantendo um artifício onde a sensação da veracidade somente é desmentida quando o olhar se aproxima demasiadamente dos trabalhos, constatando o quanto esta fatura é rigorosamente mimética.

Caetano de Almeida mostra a fraude da pintura como mímese e usa seu efeito como um trompe-l'oeil para seduzir o olho que se aproxima, sendo que neste movimento, as pinturas devolvem ao olhar, como numa cintilação, o truque que as concebeu. DidiHuberman chama semelhante movimento de princípio de mirada(...) o que vemos é o que nos olha, intenção produzida pelo caráter intimista do trabalho que aproxima o observador da pintura prometendo revelar-lhe os segredos de um mistério que está ali para ser desvendado, mas seja esta apenas a falácia da imagem como um corpo que se revela 
somente superfície. Atitude semelhante à de Porbus e Poussin no conto de Balzac, quando dizem a Frenhofer que sua obra mestra não é nada além de um muro de pintura ${ }^{12}$.

Em alguns trabalhos o artista fez buracos, que ora atravessam toda a pintura e deixam a parede aparecer como um túnel do tempo que devolve o observador à realidade, sendo que por vezes surgem como aberturas da camada pictórica que escancaram seu plano ilusório e mostram o papel branco, incólume e intocado. Segundo Didi-Huberman os pintores invocam a carne para mostrar o efeito do encarnado através da pele e do fantasma que engendra e divide a obra entre o interior do corpo e superfície. É com este fantasma que Caetano de Almeida trabalha, embora pressupondo a pintura como um truque diabólico, maquiagem e aparência atrás da qual nada se esconde. ${ }^{13}$ Não é a trama do tecido seu assunto, nem mesmo a aparência representativa dessa imagem em si que interessa, mas estes trabalhos se referem à tradição da pintura, e neste sentido alegam o corpo que a constitui. A pele é o outro dessa pintura, é a superfície com o que Caetano de Almeida trabalha e que, não sendo plana nem opaca traz o conceito de Lucidezza de Dolce para dizer que a cor não está na superfície dos corpos, mas no diáfano que os atravessa, e o diáfano é a interpenetração que se atualiza no limite do corpo $^{14}$. Desta maneira pode-se intuir que Caetano de Almeida aposta no potencial de cintilação da pintura.

Ao abordar de um modo peculiar a pintura como imagem além da superfície da pictórica, os trabalhos de Caetano de Almeida permitem repensar sua presença e todas as que o precedem através de uma visualidade lançada e revelada na sua superfície como pele. A alegoria da pintura remete ao que dá vida ao objeto artístico, à possibilidade de falar das coisas pelo corpo da arte, e embora nunca se possa acessá-la realmente ela sempre alega através de seu poder de pulsação anacrônica, tornando-se um outro. Caetano de Almeida alcança tal concepção quando revela seu procedimento mostrando que a tessitura urdida pela mão do artista não é da mesma ordem da tecelagem. É quando, pela visualidade de suas obras, problematiza o olhar como enganosa construção.

\footnotetext{
${ }^{12}$ DIDI-HUBERMAN, op. cit., p 198.

${ }^{13}$ Ibid., p 33-48.

${ }^{14}$ Ibid., p 33-34. Para Dolce limite é diferente de superfície. A superfície é uma coisa separada do corpo e, portanto opaca, já o limite é a borda faz parte do corpo e portanto possui o que ele chama de lucidezza, e a cor acontece ne sse atravessamento diáfano.
} 


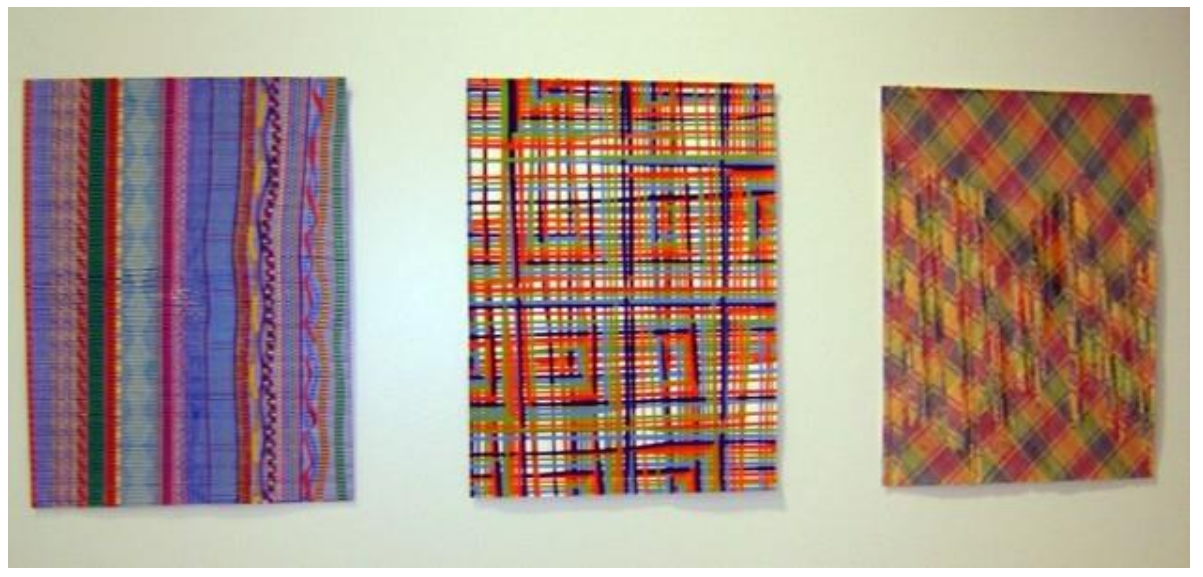

Caetano de Almeida, Exposição Borda, Pinacoteca do Estado de São Paulo, 2007, acrílica sobre papel.

$\mathrm{O}$ que pode ser apontado como elemento comum e persistente entre as tramas e buracos de Caetano de Almeida, os rasgos de Adriana Varejão e o corpo pulsante de Nuno Ramos? Para além da angústia de Frenhofer, o mestre de Poussin, a problemática da carne na pintura afirma-se como questão que impele artistas em busca de resposta às suas indagações. Retomando uma reflexão situada desde o buraco da tela de Bruneleschi, Damish assinala um sentido de tabularidade, onde mesmo de maneiras diferentes trata-se de indicar ao quadro seu pleno valor de idealidade, ou seja, sua dimensão e espessura paradoxais. ${ }^{15}$ Paradoxo que se refere ao quadro como subjetio ambíguo, pois se mostra ao outro sob seu olhar ou dissimula a si sob seu olhar.

Neste sentido, o quadro funciona como uma aporia de la proyeción, que destrói a entidade da superfície e a frustra sempre. A pintura reencarna na atualidade, desprendida da matéria que a caracteriza e pousa de modo indelével porém reconhecível. ${ }^{16}$ Para Angélica de Moraes, a pintura contemporânea resgata a memória de um fazer e principalmente de um pensar pictórico, [plasmada] em superfícies pintadas que atravessaram os séculos até nós, uma memória que aciona mecanismos de associação e leitura diacrônica, capazes de infundir alma e densidade ancestrais mesmo a expressões visuais nos novos meios digitais. ${ }^{17}$ Essa potência de ser é o que ela chama de tributo a algo imortal que se reconhece como a carne da pintura, que não se mantém à mesma maneira e que reencarna na arte contemporânea, percebendo-se nas pulsações e cintilações do passado, o coração da arte que pulsa.

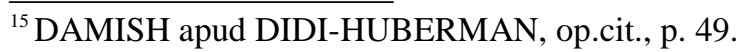

${ }^{16}$ Ibid.

${ }^{17}$ MORAES, 2005, p. 19.
} 
A alegoria deste corpo aparece, portanto, de maneiras distintas nos trabalhos destes artistas, sendo que o procedimento pictórico que cada um utiliza serve para a configuração da carne revelada na superfície como pele. Adriana Varejão constrói uma carne que duplica sua aparência, criando uma estrutura corporal densa e dramática, e na simulação deste corpo revela um outro que é o corpo da memória que permite um atravessamento no sentido de fora para seu interior e remete a um corpo para além da sua pintura, criação de um mundo simulado para falar de outrem. Nuno Ramos cria um corpo novo, onde as entranhas são sua própria pele, expõe as vísceras da pintura, cuja pele está dilacerada para fora de seu plano e seu corpo avança para o mundo, instaurando um organismo que pulsa de dentro para fora até atingir o mundo do observador, invadindo-o como carne dum outro lugar que se arremessa para dentro do corpo de quem se atreve a olhar suas entranhas.

Por sua vez, Caetano de Almeida devolve um outro corpo à história da pintura através da discussão das diferentes camadas que revestem seu próprio atravessamento no tempo, ou seja, pela pele da reprodução. Borda refere-se ao limite entre o espectador e a obra, de onde se podem observar espaços desconhecidos e considerar a relatividade dos axiomas frente aos problemas pictóricos. Se as palavras não dão conta do discurso que se impõe para pensar a imagem da arte, para Caetano de Almeida a alegoria em pintura incide para além das abordagens tradicionais e permite considerar a criação de um corpo como uma alteridade que possibilita esta troca entre vidente e visível, um cruzamento de olhares, miradas que confluem para $u m$ dentro a partir de $u m$ fora, e do interior do corpo pictórico para além de seus limites visíveis.

\section{REFERÊNCIAS}

BENJAMIN, W. Origem do Drama Barroco Alemão. Tradução Sérgio Paulo Rouanet. São Paulo: Brasiliense, 1984. 276p.

BLANCHOT, M. A Conversa Infinita. Tradução Aurélio Guerra Neto. São Paulo : Escuta, 2001. 152p.

BUCHLOH, B. Procedimentos alegóricos: apropriação e montagem na arte contemporânea. Revista do programa de pós-graduação da EBA - UFRJ, ano VII, nº 7, 2000.

DIDI-HUBERMAN, Georges. Ante el Tiempo.Traducción Oscar Antonio Oviedo Funes. Buenos Aires: Adriana Hidalgo, 2006. 
. La pintura Encarnada. Trad. Manuel Arranz. Valência: Correspondências Pré-textos - Universidade Politécnica de Valência. 2007.

. O que vemos e o que nos olha. Trad. Paulo Neves, São Paulo: 34, 1998.

MAMMI, L. texto Nuno Ramos, 1994. Disponível em:

www.sampa.art.br/saopaulo/biog\%20Nuno\%20Ramos.htm. Consultado em: 08/05/07 às 23 h35.

MORAES, A. Pintura Reencarnada.São Paulo: Paço das Artes e Imprensa Oficial, 2005.

NOVAES, Adauto (Org.) Muito além do espetáculo. São Paulo: Senac SP, 2005.

OWENS, C. O Impulso Alegórico: sobre uma teoria do pós-modernismo. Revista do Mestrado de História da Arte EBA UFRJ, Rio de Janeiro, 2º semestre. 2004.

PONTY, Merleau. O Invisível e o Invisível. Tradução de José Artur Gianotti e Armando Mora d'Oliveira. São Paulo : Perspectiva, 2007. 